\title{
Estimasi Emisi CO2 Dari Sektor Rumah Tangga Di Kota Pekanbaru
}

\author{
Yulia Fitri*, Anggi Nadia Putri, Sri Fitria Retnawaty \\ Jurusan Fisika, Fakultas MIPA dan Kesehatan, Universitas Muhammadiyah Riau, Indonesia \\ *Correspondence Email :yuliafitri@umri.ac.id
}

\begin{abstract}
The increase in $\mathrm{CO}_{2}$ emissions is in line with the increase in population and daily activities in using energy. Energy consumption is used by every household to fulfill their daily needs such as the use of LPG and electricity consumption. The purpose of this study was to determine $\mathrm{CO}_{2}$ emissions from LPG usage and electricity consumption in Pekanbaru City. The Krejcie and Morgan method is used to determine the number of samples and to calculate $\mathrm{CO} 2$ emissions is the 2006 IPCC method. The sample used in this study were 167 households in Pekanabaru City. Total $\mathrm{CO}_{2}$ emissions from households in Pekanbaru City were 40,806,386 Tons of $\mathrm{CO}_{2}$ / Month with an average of each $\mathrm{CO}_{2}$ households producing $\mathrm{CO}_{2}$ emissions of 0.1570409 Tons of $\mathrm{CO}_{2} /$ Month. Electricity consumption is the biggest contributor to $\mathrm{CO}_{2}$ emissions namely 34,602,51363 Tons of $\mathrm{CO}_{2}$ / Month and LPG contributes emissions of 6,204,424 Tons of $\mathrm{CO}_{2}$ / Month. So it can be interpreted that electricity consumption in the household sector contributes more to produce $\mathrm{CO}_{2}$ emissions.
\end{abstract}

Keywords: GHG, household sector, carbondioxide

\section{ABSTRAK}

Peningkatan emisi $\mathrm{CO}_{2}$ sejalan dengan peningkatan jumlah penduduk serta aktivitas sehari-hari dalam menggunakan energi. Konsumsi energi yang digunakan oleh setiap rumah tangga untuk memenuhi kebutuhan hidup seperti penggunaan LPG dan konsumsi daya listrik. Tujuan dari penelitian ini adalah untuk mengetahui emisi $\mathrm{CO}_{2}$ dari pemakaian LPG dan konsumsi listrik di Kota Pekanbaru. Metode Krejcie and Morgan digunakan untuk menentukan jumlah sampel dan untuk menghitung emisi $\mathrm{CO}_{2}$ adalah metode IPCC 2006. Sampel yang digunakan dalam penelitian ini adalah sebanyak 167 Rumah Tangga di Kota Pekanabaru. Total emisi CO2 dari rumah tangga di Kota Pekanbaru adalah sebesar 40.806,386 Ton CO2/Bulan dengan rata-rata setiap rumah tangga menghasilkan emisi $\mathrm{CO}_{2}$ sebesar adalah 0,1570409 Ton $\mathrm{CO}_{2} /$ Bulan. Konsumsi listrik merupakan penyumbang emisi CO2 terbesar yaitu 34.602,51363 Ton CO2/Bulan dan LPG menyumbang emisi sebesar $6.204,424$ Ton $\mathrm{CO}_{2} /$ Bulan. Maka dapat diartikan bahwa konsumsi listrik dalam sektor rumah tangga berkonstribusi lebih besar menghasilkan emisi $\mathrm{CO}_{2}$.

Kata Kunci: GRK, sektor rumah tangga, Karbondioksida

\section{Introduction}

Gas Rumah Kaca (GRK) merupakan gas-gas yang berpengaruh secara langsung maupun tidak langsung yang memberikan dampak pemanasan global terhadap perubahan iklim (Kepala Badan Pengkajian Kebijakan Iklim dan Mutu Industri tahun 2012). Berdasarkan Rudel TK tahun 2001, salah satu GRK yang paling berperan dal am memicu pemanasan global adalah karbondioksia $\left(\mathrm{CO}_{2}\right)$. Berdasarkan Jurnal Program Studi Tekni k Li ngkungan UNRI tahun 2018, penyumbang emisi GRK terbesar adalah $\mathrm{CO}_{2}$ dan lebih dari 75\% komposisi GRK adal ah $\mathrm{CO}_{2}$. GRK berasal dari sektor berbasis lahan, konsumsi energi, dan pengelolaan listrik.

Konsumen energi dibagi menjadi lima sektor pengguna, yaitu sektor industri, komersial, transportasi, rumah tangga dan lainnya. Hasil inventarisasi emisi GRK pada tahun 2015 kegiatan rumah tangga menyum bang emisi sebesar 8\%. (Berdasarkan Pusat Data dan Teknologi Informasi Kementerian Energi dan Sumber Day a Mi ineral, 2016). Peningkatan konsumsi energi final dari kegiatan rumah tangga rata-rata tumbuh sebesar 1,58\% per tahun dalam kurun waktu 2000-2015. Energi final yang dikonsumsi dari kegiatan rumah tangga pada tahun 2015 adalah listrik 14,54\%, LPG 13,95\%, minyak tanah 1,04\%, sedangkan kayu bakar 70,43\% dan gas 0,04\%.Emisi yang dihasilkan kegiatan rumah tangga adalah salah satunya $\mathrm{CO}_{2}$ yang berasal dari LPG, minyak tanah, kayu bakar dan konsumsi daya listrik (Kepala Badan Pengkajian Kebijakan Iklim dan Mutu Industri tahun 2012) (BPS, 2018).

Received: 17 July 2020, Accepted : October 2020 - Jurnal Photon Vol.11 No.1

DOI : https://doi.org/10.37859/jp.v17i1.2061

PHOTON is licensed under a Creative Commons Attribution-ShareAlike 4.0 International License 


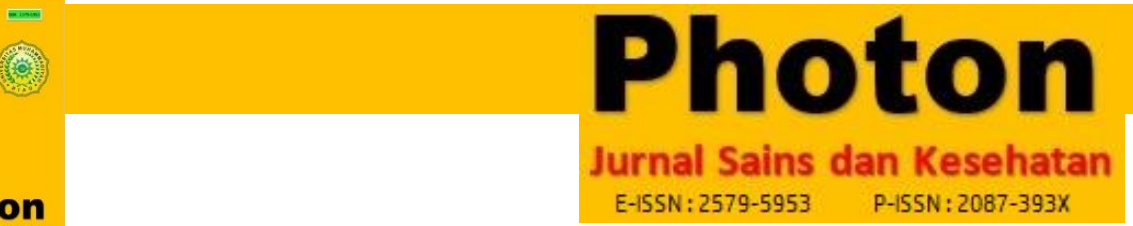

http://ejurnal.umri.ac.id/index.php/photon

Kota Pekanbaru merupakan salah satu kota yang mengalami laju pertumbuhan yang sangat cepat dan kegiatan penduduk yang tinggi. Pada tahun 2010-2017 Kota Pekanbaru mengalami laju pertumbuhan penduduk 20,28\% dengan jumlah penduduk 1.091.088. Pekanbaru memiliki luas wilayah $632,3 \mathrm{Km}^{2}$ atau $63.230 \mathrm{Ha}$ yang terdiri dari 12 Kecamatan yang seluruhnya merupakan permukiman. Berdasarkan kondisi tersebut, maka perlu dilakukan penelitian untuk menghitung produksi emisi $\mathrm{CO}_{2}$ yang dihasilkan dari kegiatan rumah tangga berupa penggunaan bahan bakar memasak dan onsumsi daya listrik di Kota Pekanbaru (BPS, 2018).

\section{The Methods}

\section{Pengumpulan DataSekunder}

Data yang digunakan adalah total seluruh rumah tangga di Kota Pekanbaru tahun 2017 dan jumlah rumah tangga disetiap Kecamatan di Kota Pekanbaru tahun 2017 yang terdiri dari 12 Kecamatan. Setelah diperoleh data sekunder, maka ditentukan jumlah sampel yang akan diambil.

\section{Menentukan Jumlah Sampel}

Penentuan jumlah sampel dalam penelitian ini menggunakan metode acak yaitu menggunakan metode Krejcie and Morgan. Untuk

menghitung total sampel yang akan diambil menggunakan Persamaan 1.

$n=\frac{x^{2} N P(1-P)}{(N-1) d^{2}+x^{2} P(1-P)}$

Kemudian untuk mendapatkan berapa sampel disetiap Kecamatan di Kota Pekanbaru menggunakan Pers amaan 2.

$\mathrm{n}_{\mathrm{i}}=\mathrm{n}\left(\frac{\mathrm{N}_{\mathrm{i}}}{\mathrm{N}}\right)$.

(Krejcie, R. V., \& Morgan, D. W., 1970).

Sehingga total jumlah sampel yang digunakan dalam penelitian ini adalah 167 Rumah Tangga dari 12 kecamatan di kota Pekanbaru

\section{Menghitung Emisi $\mathrm{CO}_{2}$ di Kota Pekanbaru}

Menghitung produksi emisi $\mathrm{CO}_{2}$ dari kegiatan rumah tangga dilakukan dengan menggunakan metode IPCC

(Intergovernmental Panel on Climate Change).

1) Emisi $\mathrm{CO}_{2}$ Dari LPG.

Perhitungan yang digunakan untuk menentukan emisi $\mathrm{CO}_{2}$ dari pemakaian bahan bakar memasak dihasilkan dari jumlah bahan bakar memasak yang digunakan tiap bulannya dalam tiap rumah tangga. Emisi $\mathrm{CO}_{2}$ LPG dapat dihitung dengan menggunakan Persamaan 3.

EmisiCO $_{2}=$ Konsumsi Bahan Bakar $\times$ FE $\times$ NCV.

\section{Keterangan:}

FE LPG $=63.100 \mathrm{Kg} / \mathrm{Tj}$.

NCV LPG $=0,0000473 \mathrm{Tj} / \mathrm{Kg}(\mathrm{IPCC}, 2006)$

2) Emisi $\mathrm{CO}_{2}$ Dari Konsumsi Daya Listrik

Perhitungan yang digunakan untuk menentukan emisi $\mathrm{CO}_{2}$ dari listrik dihasilkan dari jumlah konsumsi listrik dalam setiap rumah tangga/bulannya di Kota Pekanbaru. Emisi $\mathrm{CO}_{2}$ listrik dapat dihitung dengan menggunakan Persamaan 4.

EmisiCO $_{2}=$ Konsumsi Daya Listrik×FE.

Keterangan:

FE listrik = 0,794 $\mathrm{Kg} \mathrm{CO}_{2} / \mathrm{kWh}$ (IPCC, 2006)

Received: 17 July 2020, Accepted : October 2020 - Jurnal Photon Vol.11 No.1

DOI : https://doi.org/10.37859/jp.v77i7.2061

PHOTON is licensed under a Creative Commons Attribution-ShareAlike 4.0 International License 


\section{Menghitung Rata-Rata Emisi $\mathrm{CO}_{2}$ Berdasarkan LPG dan Konsumsi Listrik}

Rata-rata emisi $\mathrm{CO}_{2}$ dari LPG dan listrik dapat dilakukan dengan cara membagi total emisi $\mathrm{CO}_{2}$ sampel dengan total sampel yang diambil di Kota Pekanbaru. Perhitungan rata-rata emisi $\mathrm{CO}_{2}$ berdasarkan LPG dan konsumsi listrik dapat di lakukan dengan cara menggunakan Persamaan 5 (Sasmita, 2018)

Rata - Rata Emisi $\mathrm{CO}_{2}=$

$\underline{\text { Total Emisi } \mathrm{CO}_{2} \text { Sampel }}$

Total Sampel RT

\section{Menentukan Total Emisi $\mathrm{CO}_{2}$ di Kota Pekanbaru}

a) Menghitung total emisi $\mathrm{CO}_{2}$ Berdasarkan LPG dan konsumsi listrik

Perhitungan total emisi $\mathrm{CO}_{2}$ dari LPG, listrik dan bahan bakar motor dapat dilakukan dengan cara menggunakan persamaan 6 dan 7 (Sasmita, 2018)

Total Emisi $\mathrm{CO}_{2} \mathrm{LPG}=$ Rata-Rata Emisi $\mathrm{CO}_{2} \times$ Jumlah RT

Total Emisi $\mathrm{CO}_{2}$ Listrik =Rata-Rata Emisi $\mathrm{CO}_{2} \times$

Jumlah RT..

b) Menghitung Total Seluruh Emisi $\mathrm{CO}_{2}$ di Kota Pekanbaru.

Total emisi $\mathrm{CO}_{2}$ dari kegiata rumah tangga dapat dilakukan dengan cara menjumlahkan total emisi $\mathrm{CO}_{2}$ LPG dan emisi $\mathrm{CO}_{2}$ listrik di Kota Pekanbaru.

\section{Result and Discussion}

\section{a. Jumlah Pemakaian LPG}

Berdasarkan hasil kuisioner yang disebarkan pada rumah tangga di Kota Pekanbaru menggunakan LPG dengan jenis tabung $3 \mathrm{Kg}, 5,5 \mathrm{Kg}$ dan $12 \mathrm{Kg}$. Total pemakaia LPG berdasarkan jumlah pemakaian LPG (Kg/Bulan) rum ah tangga di Kota Pekanbaru dengan 167 sampel yaitu sebanyak $1.351 \mathrm{Kg} /$ Bulan. Rata-rata pemakaian setiap rumah tangga di Kota Pekanbaru yaitu $8 \mathrm{Kg} /$ Bulan atau 0,26 Kg/Hari. Rumah tangga di Kota Pekanbaru yang menggunakan jenis tabung $3 \mathrm{Kg}$ yaitu sebanyak 131 rumah tangga, dengan total pemakaian $981 \mathrm{Kg} / \mathrm{Bulan}$ dan rata-rata pemakaian 7,4 Kg/Bulan/Rumah Tangga. Sedangkan terdapat 12 rumah tangga yang menggunakan jenis tabung 5,5 Kg, dengan total pemakaian $88 \mathrm{Kg} /$ Bulan dan rata-rata pemakaian 7,3 Kg/Bulan/Rumah Tangga. Untuk jenis tabung $12 \mathrm{Kg}$ terdapat 24 rumah tangga dengan total pemakaian $282 \mathrm{Kg} / \mathrm{Bulan}$ dan rata-rata pemakaian setiap rumah tangg $11,7 \mathrm{Kg} /$ Bulan. Rumah tangga yang menggunakan jenis tabung $12 \mathrm{Kg}$ memiliki nilai rata-rata pemakaian yang paling tinggi dibandingkan dengan jenis tabung lainnya.

Berdasarkan data badan pusat statistik jumlah rumah tangga di Kota Pekanbaru sebanyak 259.849 rumah tangga. Total pemakaian LPG yang dihabiskan rumah tangga di Kota Pekanbaru dapat diperoleh dengan mengkalikan rata-rata pemakaian setiap rumah tangga dengan jumlah rumah tangga di Kota Pekanbaru. Maka didapatkan total pemakaian LPG yang dihabiskan rumah tangga di Kota Pekanbaru sebanyak 2.078.792 $\mathrm{Kg} /$ Bulan.

\section{b. Jumlah Konsumsi Listrik di Kota Pekanbaru.}

Besar daya listrik yang digunakan rumah tangga menyesuaikan dengan kebutuhan listrik rumah tersebut. Daya listrik yang digunakan oleh rumah tangga di Kota Pekanbaru adalah 450 Volt, 900 Volt, 1300 Volt, 2200 Volt dan 3500 Volt. Rumah tangga di Kota Pekanbaru lebih banyak menggunakan daya listrik 1300 Volt yaitu s ebanyak 65 rumah tangga dengan persentase 39\% dari total sampel rumah tangga. Daya listrik yang paling sedikit digunakan oleh rumah tangga di Kota Pekanbaru, yaitu 3500 volt yaitu $3 \%$ dari total sampel rumah tangga di Kota Pekanbaru. Dari hasil penelitian ini dengan 167 sampel di dapatkan total konsumsi listrik rumah tangga di Kota Pekanbaru sebanyak $27.872 \mathrm{kWh} /$ Bulan dengan rata-rata konsumsi listrik setiap rumah tangga 166,8 $\mathrm{kWh} /$ bulan atau $5,56 \mathrm{kWh} / \mathrm{hari}$

Received: 17 July 2020, Accepted : October 2020 - Jurnal Photon Vol.11 No.1

DOI : https://doi.org/10.37859/jp.v17i7.2061

PHOTON is licensed under a Creative Commons Attribution-ShareAlike 4.0 International License 
Photon

Jurnal Sains dan Kesehatan

E-15SN:2579-5953 P-15SN : 2087-393X

http://ejurnal.umri.ac.id/index.php/photon

Total konsumsi listrikyang digunakan rumah tangga di Kota pekanbaru diperoleh dengan mengalikan rata -rata konsumsi listrik (kWh/Bulan) yang digunakan pada setiap rumah tangga dengan jumlah rumah tangga di Kota Pekanbaru. Jumlah rumah tangga di Kota Pekanbaru sebanyak 259.849 rumah tangga, ,maka didapatkan total konsumsi listrik (kWh/Bulan) yang digunakan rumah tangga di Kota Pekanbaru sebanyak sebesar 43.602.662,2 $\mathrm{kWh} /$ Bulan.

\section{c. $\quad$ Emisi $\mathrm{CO}_{2}$ Dari LPG}

Emisi $\mathrm{CO}_{2}$ LPG dapat diperoleh dengan mengkalikan pemakaian LPG dengan NCV dan faktor emisi LPG (Persamaan 3). Emisi $\mathrm{CO}_{2}$ yang diperoleh pada setiap rumah tangga di Kota Pekanbaru yaitu sebanyak 23,87704 $\mathrm{Kg} \mathrm{CO}$ /Bulan. Total emisi $\mathrm{CO}_{2}$ LPG seluruh rumah tangga di Kota Pekanbaru yang dihasilkan adalah 6.204.424,96696 $\mathrm{Kg} \mathrm{CO}_{2} /$ Bulan.

Contoh perhitungan emisi $\mathrm{CO}_{2} \mathrm{LPG}$

Emisi $\mathrm{CO}_{2}$ Dari Penggunaan LPG yang menggunakan Tabung $3 \mathrm{Kg}$.

Diketahui:

$\mathrm{FE}=63.100 \mathrm{Kg} / \mathrm{Tj}$

$\mathrm{NCV}=0,0000473 \mathrm{Tj} / \mathrm{Kg}$

Jumlah LPG $=4$ Tabung/bulan

Jumlah Konsumsi $\mathrm{LPG}=4 \times 3=12 \mathrm{Kg}$

Perhitungan:

Emisi $\mathrm{CO}_{2}=$ Jumlah Konsumsi LPG $\times \mathrm{FE} \times \mathrm{NCV}$

Emisi $\mathrm{CO}_{2}=12 \times 63100 \times 0,0000473$



\section{d. Emisi $\mathrm{CO}_{2}$ Dari Listrik}

Emisi $\mathrm{CO}_{2}$ dari konsumsilistrik dapat diperoleh dengan mengalikan faktor emisi listrik dengan besarnya lis trik yang dikonsumsi oleh satu rumah tangga setiap bulannya yang ada di Kota Pekanbaru (Persamaan 4). Total emisi $\mathrm{CO}_{2}$ listrik di Kota Pekanbaru yaitu sebesar 34.414.193,6808 $\mathrm{Kg} \mathrm{CO}_{2} /$ Bulan dengan emisi setiap rumah tangganya sebesar 132,4392 $\mathrm{Kg} \mathrm{CO}_{2} /$ Bulan.

Contoh perhitungan emisi $\mathrm{CO}_{2} \mathrm{LPG}$

Diketahui:

$\mathrm{FE}=0,0794 \mathrm{Kg} \mathrm{CO}_{2} / \mathrm{kWh}$

Konsumsi Daya Listrik $=192 \mathrm{kWh}$

Perhitungan:

Emisi CO2 $=$ Konsumsi Daya Listrik $\times F E$

Emisi CO2 $=192 \times 0,794$

Emisi $\mathrm{CO} 2=\mathbf{1 5 2}, \mathbf{4 4 8} \mathrm{Kg} \mathrm{CO}_{2} /$ Bulan

\section{e. Total Emisi $\mathrm{CO}_{2}$ di Kota Pekanbaru}

Total emisi $\mathrm{CO}_{2}$ di Kota Pekanbaru didapatkan dengan menjumlahkan emisi $\mathrm{CO}_{2} \mathrm{LPG}$ dan emisi $\mathrm{CO}_{2}$ listrik . Metode yang digunakan untuk menghitung total emisi $\mathrm{CO}_{2}$ adalah metode IPCC 2006 dan kalkulator jejak karbon.Total emisi emisi $\mathrm{CO}_{2}$ di Kota Pekanbaru dapat dilihat pada Tabel 1.

Total emisi CO2 yang berasal dari LPG dan listrik dengan menggunakan metode IPCC 2006 yaitu sebesar 40.806.938,6 Kg CO2/Bulan atau 40.806,386 Ton CO2/Bulan. Rata-rata emisi CO2 yang dihasilkan oleh setiap rumah tangga adalah 157,0409684 Kg CO2/Bulan 0,15704 Ton CO2/Bulan. Emisi CO2 listrik lebih besar dibandingkan dengan emisi CO2 LPG dengan persentase 85\% (listrik) dan 15\% (LPG). Maka dapat diartikan bahwa konsumsi listrik dalam aktivitas rumah tangga berkonstribusi lebih besar dalam menghasilkan emisi CO2 Total emisi $\mathrm{CO}_{2}$ dapat dilakukan juga dengan cara perhitungan kalkulator jejak karbon. Salah satu jenis kalkulator jejak karbon yaitu menurut the resurgence carbon dioxide calculator. Kalkulator jejak karbon ini yaitu

Received: 17 July 2020, Accepted : October 2020 - Jurnal Photon Vol.11 No.1

DOI : https://doi.org/10.37859/jp.v17i1.2061

PHOTON is licensed under a Creative Commons Attribution-ShareAlike 4.0 International License 
kalkulator online yang digunakan dilayar. Penggunaan the resurgence carbon dioxidecalculator dapat dilakukan secara mudah dan akurat dengan cara isi fomulir dengan angka atau jumlah pemakaian pada setiap area.

Menurut the resurgence carbon dioxide calculator total emisi CO2 di Kota Pekanbaru berdasarkan jumlah rumah tangga didapatkan dengan hasil sebesar 21.867.333 Kg CO2/Bulan atau 21.867,333 Ton C02/Bulan, dimana LPG menyumbang emisi CO2 sebesar 3.118,188 Ton CO2/Bulan dan listrik menyumbang emisi CO2 sebesar 18.749,145 Ton CO2/Bulan. Total emisi yang menggunakan metode IPCC 2006 dengan total emis i yang menggunakan kalkulator jejak karbon berbeda, hal ini dikarenakan faktor emisi yang digunakan metode IPCC 2006 dan kalkulator jejak karbon berbeda.

Tabel 1. Total Emisi $\mathrm{CO}_{2}$ di Kota Pekanbaru

\begin{tabular}{clcc} 
No & Emisi CO2 & $\begin{array}{c}\text { Total Seluruh Emisi CO2 } \\
\text { (Ton CO2/Bulan) } \\
\text { Perhitungan Kalkulator } \\
\text { Karbon }\end{array}$ & $\begin{array}{c}\text { Total Seluruh Emisi CO2 } \\
\text { (Ton/Bulan) IPCC 2006 }\end{array}$ \\
\hline 1 & LPG & $3.118,188$ & $6.204,424$ \\
2 & Listrik & $18.749,145$ & $34.602,51363$ \\
\hline & Total EmisiCO2 & $21.867,333$ & $40.806,386$ \\
\hline
\end{tabular}

\section{Conclusion}

Kesimpulan dari penelitian ini adalah:

1. Rata-rata emisi CO2 pemakaian LPG dan listrik yang dihasilkan oleh setiap rumah tangga di Kota Pekanbaru adalah 0,1570409684 Ton C02/Bulan yang masing-masing disumbangkan oleh pemakaian LPG sebesar LPG 0,02387704 Ton $\mathrm{CO}_{2}$ /Bulan dan konsumsi listrik sebesar 0,1324392 Ton $\mathrm{CO}_{2} / \mathrm{Bulan}$

2. Total emisi CO2 di Kota Pekanbaru adalah 40.806,9386 Ton CO2/Bulan, dimana emisi CO2 yang dihasilkan di Kota Pekanbaru dari pemakaian LPG yaitu sebanyak 6.204,4249 Ton CO2/Bulan dan konsumsi listriksebanyak 34.602, 51363 Ton CO2/Bulan.

3. Konsumsi listrik lebih berkonstribusi lebih besar dibandingkan pemakian LPG dalam menghasilkan emisi $\mathrm{CO} 2$.

\section{References}

Badan Pusat Statistik. (2018). Kota Pekanbaru Dalam Angka 2018. https://pekanbarukota.bps.go.id/publication/2018/08/16/79b0025f1290a0536af3d9ab/kotapekanbaru-dalam-angka-2018.html. Diakses pada Tanggal 16 Agustus 2018.

Intergovenmental Panel on Climate Change (IPCC). (2006). Guidelines for National Greenhouse Gas Inv ento res. Institute for Global Environmental Strategis (IGS). Hayana. Japan.

Kepala Badan Pengkajian Kebijakan Iklim dan Mutu Industri. (2012). Draft Petunjuk Teknis Perhitungan E mi si Gas Rumah Kaca (GRK) di Sektor Industri. Jakarta.

Kementrian Energi dan Sumber Daya Mineral Direktorat Jenderal Ketenagalistrikan. (2016). Faktor Emisi Gas Rumah Kaca Sistem Interkoneksi Tahun 2014.

Krejcie, R. V., \& Morgan, D. W. (1970). Determining sample size for research activities. Educational and psychologicalmeasurement, 30(3), 607-610.

Nugrahayu, Qorry., Nabila Khumatra Nurjannah dan Luqman Hakim. (2017). Estimasi Emi si Karbondioaksi da Darai Sektor Permukiman di Kota Yogyakarta Menggunakan IPCC Guidelines. Jurnal Sainsdan Teknologi Lingkungan. 9 (1)25-36.

Received: 17 July 2020, Accepted : October-December 2020 - Jurnal Photon Vol.11 No.1

DOI : https://doi.org/10.37859/jp.v17i7.2061

PHOTON is licensed under a Creative Commons Attribution-ShareAlike 4.0 International License 
Photon

Jurnal Sains dan Kesehatan

E-15SN:2579-5953 P-15SN : 2087-393X

http://ejurnal.umri.ac.id/index.php/photon

Pusat Data dan Teknologi Informasi Kementerian Energi dan Sumber Daya Mineral. (2016). Data Inventory Emisi GRK Sektor Energi. Jakarta Pusat.

Rudel TK (2001). Sequatering Carbon In Tropical Forest: Experiment, Police Implication, And Calimatic Change. Society and Natural Resaurce. 14 (1) 525-531.

Sasmita, Aryo., Jecky Asmura dan Ivnaini Andesgur (2018). Analisi Carbon Footprint Yang dihasilkan Akti vi tas Rumah Tangga di KelurahaLimbungan Baru Kota Pekanbaru. Jurnal Teknik. 16 (16) 96-105.

Wiratama, I Gusti Made (2016). Jejak Karbon Konsumsi LPG dan Listrik Pada Aktivitas Rumah Tangga di Kota Denpasar,

Bali.

Skripsi.

Universitas

Udayana.

Received: 17 July 2020, Accepted : October-December 2020 - Jurnal Photon Vol.11 No.1

DOI : https://doi.org/10.37859/jp.v17i1.2061

PHOTON is licensed under a Creative Commons Attribution-ShareAlike 4.0 International License 